\title{
Glutathione S-Transferases and Chloroform Toxicity in Streptozotocin-Induced Diabetic Rats
}

\author{
Yoko ANIYA, Yoshihiko OJIRI, Ryuji SUNAGAWA', Keiji MURAKAMI', \\ Guan ZHENZHONG ${ }^{1}$ : , Goro MIMURA ${ }^{1}$ and Matao SAKANASHI ${ }^{2}$ \\ Laboratory of Physiology and Pharmacology. School of Health Sciences, \\ ${ }^{1}$ Second Department of Internal Medicine and ${ }^{2}$ Department of Pharmacology, \\ School of Medicine. Faculty of Medicine. University of the Ryukyus. \\ Okinawa 903-01. Japan
}

Accepted March 16, 1989

\begin{abstract}
The glutathione S-transferase activity in liver and kidney cytosol was significantly decreased in short term diabetes induced with streptozotocin, whereas no decrease in the transferase was observed in phenobarbital-treated diabetic rats. Toxicity of chloroform was potentiated in streptozotocin- or phenobarbital-treated rats. The decrease in liver cytosolic and microsomal glutathione S-transferase activity was observed in long term diabetic rats, and only microsomal transferase activity was restored by insulin treatment. There was no release of glutathione $S$ transferases into the serum in the diabetic rats, and the transferases were not inhibited by streptozotocin in vitro. These results showed that glutathione $\mathrm{S}$ transferase activity decreased during diabetes, and this decrease may contribute to altering drug metabolism and toxicity in diabetes.
\end{abstract}

Glutathione S-transferases (EC 2.5.1.18) catalyze the reaction of glutathione conjugation with many xenobiotics and their reactive metabolites formed via the cytochrome P-450 monooxygenase system $(1,2)$. Evidence showed that drug metabolism and toxicity are altered in chemically-induced diabetes (3-7): however, there have been very few investigations of glutathione $\mathrm{S}$-transferases in diabetic animals. It has been reported that hepatic glutathione S-transferases are altered by hepatotoxic chemicals and released into the serum $(8,9)$. In the present study, the effect of diabetes on glutathione $\mathrm{S}$-transferase and chloroform toxicity was investigated.

\section{Materials and Methods}

Animal treatment for short term diabetes: Male Sprague-Dawley rats (Clea Japan, Inc., Tokyo), weighing 165-175 g. were used. The animals were starved for $16 \mathrm{hr}$ prior to receiving $80 \mathrm{mg} / \mathrm{kg}$ streptozotocin in distilled water.

\footnotetext{
- Present address: Keshan Disease Institute, Harbin Medical University. China.
}

intraperitoneally (i.p.). Controls received an equivalent volume of water $(0.3 \mathrm{ml} / 100 \mathrm{~g})$. The rats were kept in a stainless steel wire cage with a $12 \mathrm{hr}$ light-dark cycle and given a commercial laboratory chow (Clea, Japan, Inc., Tokyo) and water ad libitum. Seven days after the streptozotocin treatment, the animals were given $0.2 \mathrm{ml} / \mathrm{kg}$ chloroform, i.p., in a $30 \%$ olive oil solution. In the case of phenobarbital treatment, streptozotocin-diabetic and control rats were given phenobarbital sodium at $75 \mathrm{mg} / \mathrm{kg}$, i.p., a day for 2 days, and chloroform was administered $18 \mathrm{hr}$ after the last injection of phenobarbital. The rats were anesthetized with pentobarbital at $30 \mathrm{mg} / \mathrm{kg}$. i.p. $5 \mathrm{hr}$ after chloroform treatment. Immediately after the abdomen was opened by a midline incision, blood was collected from the inferior vena cava; and the liver and kidney were removed, weighed and perfused with $1.15 \%$ potassium chloride solution. The perfused liver and kidney were separately homogenized with a Teflon-glass homogenizer in 2 volumes of the same solution. The homogenate was centrifuged at $9,000 \times \mathrm{g}$ for 30 
min, and the supernatant fraction was further centrifuged at $105,000 \times \mathrm{g}$ for $60 \mathrm{~min}$. The supernatant thus obtained was used as the cytosol fraction, and the pellets from the livers were washed with $1.15 \%$ potassium chloride solution at $105,000 \times \mathrm{g}$ for $60 \mathrm{~min}$ and then used as microsomes after resuspension in the same solution.

Animal treatment for long term (chronic) diabetes: Streptozotocin (100 $\mathrm{mg} / \mathrm{kg}$, i.p.) was administered to Sprague-Dawley rats under the same conditions as described for the short term diabetes, and the rats were killed 6 weeks later by decapitation. In the insulin treated group, rats were given insulin (4 units/animal/day, s.c.) from 3 days after streptozotocin injection until the day before killing. Liver cytosol and microsomes were prepared by the same method as described for the short term diabetic rats, except for twice washing of microsomes.

Enzyme assay: Glutathione S-transferase activity in the liver, kidney and serum was measured under the same conditions according to the method of Habig et al. (10). and activation of the microsomal enzyme by $\mathrm{N}$-ethylmaleimide was done by the method of Morgenstern et al. (11). Aniline hydroxylase activity in liver microsomes was assayed under the same conditions as previously described (12). The serum glucose level and glutamate-pyruvate transaminase (GPT) activity were measured by using kits from Sinotest Laboratory. Ltd., Kanagawa, and
Eiken Kagaku Ltd., Tokyo, respectively. In the in vitro experiments, liver cytosol and microsomes prepared from nontreated rats were incubated with $10 \mathrm{mM}$ streptozotocin in $0.1 \mathrm{M}$ potassium phosphate buffer $(\mathrm{pH} \mathrm{7.4)}$ in the presence of a NADPH generating system as described previously (12) at $37^{\circ} \mathrm{C}$ for $20 \mathrm{~min}$, and then glutathione $\mathrm{S}$-transferase activity was measured. Protein concentration in the cytosol and microsomes was determined by the method of Lowry et al. (13).

Statistical analysis: Data are expressed as the mean \pm S.D. Significance of the difference was calculated by Student's $t$-test, and $P$ values $<0.05$ were taken as significant.

Chemicals: Streptozotocin and reduced glutathione were purchased from the Sigma Chemical Co.. St. Louis, MO. 1-Chloro-2.4dinitrobenzene (CDNB) and phenobarbital sodium were obtained from Wako Pure Chemical Industries, Ltd., Tokyo. Pentobarbital sodium was from Abbott Laboratories, North Chicago, IL. Lente insulin was purchased from Novo Industry, Denmark. 1.2Dichloro-4-nitrobenzene (DCNB) and 1.2epoxy-3-(p-nitrophenoxy) propane (EPNP) were obtained from Eastman Kodak, Co., Rochester, NY. Aniline was purified by distillation. All other chemicals were of analytical reagent grade.

\section{Results}

Tables 1 and 2 represent the change in body and tissue weights and the serum parameters

Table 1. Body and tissue weights in short term diabetic rats

\begin{tabular}{|c|c|c|c|}
\hline Treatment & $\begin{array}{l}\text { Body } \\
\text { (g) }\end{array}$ & $\begin{array}{c}\text { Liver } \\
(\mathrm{g} / 100 \mathrm{~g} \mathrm{~b} . \mathrm{w} .)\end{array}$ & $\begin{array}{c}\text { Kidney } \\
(\mathrm{g} / 100 \mathrm{~g} \text { b.w.) }\end{array}$ \\
\hline \multicolumn{4}{|l|}{ Nontreated } \\
\hline Control & $264.3 \pm 9.2$ & $5.00 \pm 0.51$ & $0.79 \pm 0.07$ \\
\hline $\mathrm{CHCl}_{3}$ & $255.9 \pm 13.5$ & $4.60 \pm 0.13^{*}$ & $0.84 \pm 0.14$ \\
\hline STZ & $214.3 \pm 26.3^{*}$ & $4.68 \pm 0.19$ & $1.09 \pm 0.09^{*}$ \\
\hline $\mathrm{STZ}+\mathrm{CHCl}_{3}$ & $231.8 \pm 8.7^{*}$ & $4.46 \pm 0.16^{*}$ & $1.00 \pm 0.08^{* *}$ \\
\hline \multicolumn{4}{|l|}{ PB treated } \\
\hline Control & $259.2 \pm 15.2$ & $4.97 \pm 0.34$ & $0.72 \pm 0.03$ \\
\hline $\mathrm{CHCl}_{3}$ & $270.0 \pm 11.7$ & $4.67 \pm 0.34$ & $0.73 \pm 0.05$ \\
\hline STZ & $232.0 \pm 22.9$ & $5.40 \pm 0.18^{*}$ & $0.96 \pm 0.06^{*}$ \\
\hline $\mathrm{STZ}+\mathrm{CHCl}_{3}$ & $228.0 \pm 11.5^{* \# \#}$ & $5.45 \pm 0.43^{\#}$ & $1.04 \pm 0.19^{*}$ \\
\hline
\end{tabular}

Streptozotocin (STZ, $80 \mathrm{mg} / \mathrm{kg}$, i.p.), chloroform $\left(\mathrm{CHCl}_{3}, 0.2 \mathrm{ml} / \mathrm{kg}\right.$, i.p.) and phenobarbital (PB, $75 \mathrm{mg} /$ $\mathrm{kg}$, i.p.) were given to rats. Values represent the mean \pm S.D. from 4 to 11 rats. Analysis of variance: *P<0.05, control vs. treated: $\mathrm{P}<0.05, \mathrm{CHCl}_{3}$ vs. STZ $+\mathrm{CHCl}_{3}$. 
Table 2. Serum parameters in short term diabetic rats

\begin{tabular}{cccc}
\hline Treatment & $\begin{array}{c}\text { Glucose } \\
(\mathrm{mg} / \mathrm{dl})\end{array}$ & $\begin{array}{c}\text { SGPT } \\
(\text { Karmen unit) }\end{array}$ & $\begin{array}{c}\mathrm{SGST} \\
(\mu \mathrm{mol} / \mathrm{ml})\end{array}$ \\
$\begin{array}{c}\text { Nontreated } \\
\text { Control }\end{array}$ & $189.0 \pm 20.3$ & $16.5 \pm 1.8$ & $0.08 \pm 0.01$ \\
$\mathrm{CHCl}$ & $189.5 \pm 17.4$ & $32.7 \pm 15.4^{*}$ & $0.10 \pm 0.03$ \\
$\mathrm{STZ}$ & $440.9 \pm 69.3^{*}$ & $24.8 \pm 6.3^{*}$ & $0.08 \pm 0.01$ \\
$\mathrm{STZ}+\mathrm{CHCl}_{3}$ & $397.2 \pm 34.9^{*}$ & $60.9 \pm 30.2^{* *}$ & $0.09 \pm 0.02$ \\
$\mathrm{~PB}$ treated & & & \\
Control & $153.6 \pm 10.1$ & $17.6 \pm 2.8$ & $0.06 \pm 0.01$ \\
$\mathrm{CHCl}$ & $152.2 \pm 7.7$ & $798.3 \pm 555.5$ & $3.00 \pm 2.12$ \\
$\mathrm{STZ}$ & $434.6 \pm 58.1^{*}$ & $27.5 \pm 5.7^{*}$ & $0.07 \pm 0.01$ \\
$\mathrm{STZ}+\mathrm{CHCl}_{3}$ & $288.3 \pm 75.5^{*}+$ & $5342.4 \pm 5019.7$ & $8.83 \pm 8.53$ \\
\hline
\end{tabular}

Rats were given chemicals as described in Table 1 and glucose. glutamate-pvruvate transaminase (SGPT) and glutathione S-transferase (SGST) in serum were measured as described in Materials and Methods. Values represent the mean $=5$.D. from 4 to 11 rats. Analysis of variance: $P<0.05$. control vs. treated; ${ }^{\#} \mathrm{P}<0.05, \mathrm{CHCl}_{3}$ vs. STZ $+\mathrm{CHCl}_{3} ; \uparrow \mathrm{P}<0.05$, STZ vs. STZ $+\mathrm{CHCl}_{3}$

in short term diabetic rats. A significant decrease in body weight ( $81 \%$ of the control) and an increase in serum glucose levels $(440.9 \pm 69.3 \mathrm{mg} / \mathrm{dl})$ were observed in streptozotocin-treated rats. These results showed that rats treated with streptozotocin were in a diabetic state. In the phenobarbital treated groups, the serum glucose level (434.6 558.1 $\mathrm{mg} / \mathrm{dl}$ ) in the diabetic rats was the same as that in the nontreated rats, but it was significantly decreased $(288.3 \pm 75.5 \mathrm{mg} / \mathrm{dl})$ by chloroform treatment. Liver weight per $100 \mathrm{~g}$ body weight was decreased by chloroform treatment. Kidney weight was significantly increased by streptozotocin treatment. and the kidney seemed to become hydronephrotic. A phenomenon of alteration of tissue weights similar to that shown in nontreated rats was observed in the phenobarbital treated groups except that an increased liver weight in the diabetic animals was noted.

Serum GPT activity in nontreated rats was increased to 1.9 -times that of the control after chloroform treatment and 3.6-times in the combined streptozotocin and chloroform groups. Serum glutathion S-transferase activity was not increased by chloroform treatment. In phenobarbital-treated groups, GPT activity was markedly increased to 45 -times the control level by chloroform alone and to 303-times the control level by the combina tion of chloroform and streptozotocin. Serum glutathione S-transferase activity after chloro- form treatment was 46 -times the control level in nondiabetic and 138-times the control level in the diabetic rats. However, these marked elevations of both serum GPT and glutathione S-transferase activities were not statistically significant because of the broad deviation at high concentrations.

As shown in Table 3, liver cytosolic glutathione $\mathrm{S}$-transferase activity in nontreated groups was significantly decreased to $79 \%$ of the control by treatment with chloroform, to $75 \%$ with streptozotocin and to $67 \%$ by a combination of both chemicals. Kidney cytosolic glutathione S-transferase activity was significantly decreased only in streptozotocindiabetes. In phenobarbital treated rats, the diabetic state alone caused no significant decreased in glutathione S-transferase activity in both the liver and kidney. Aniline hydroxylation was increased slightly $(116 \%$ of the control) in the diabetic rats of the nontreated group, but the hydroxylase activity reached the level of the control after they were given chloroform. In the phenobarbital treated rats, the hydroxylation was not altered in the diabetic state. Chloroform treatment caused a significant decrease in aniline hydroxylation in both nontreated and phenobarbital treated groups.

In chronic diabetic rats, body weight was decreased to $44 \%$ of the control and recovered to $93 \%$ in insulin-treated rats. Glutathione Stransferase activity was not detected in the 
Table 3. Glutathione S-transferase and aniline hydroxylase activities in short term diabetic rats

\begin{tabular}{|c|c|c|c|c|}
\hline \multirow{3}{*}{ Treatment } & & \multicolumn{2}{|c|}{ GST for CDNB $(\mu \mathrm{mol} / \mathrm{mg} / \mathrm{min})$} & \multirow{3}{*}{$\begin{array}{c}\text { Aniline hydroxylase } \\
\text { (p-Aminophenol } \\
\text { nmol/mg/20 min) }\end{array}$} \\
\hline & & & & \\
\hline & & Liver cytosol & Kidney cytosol & \\
\hline - - & -- & - & .. $\quad---$ & $\begin{array}{lll}- & - & -\end{array}$ \\
\hline \multicolumn{5}{|l|}{ Nontreated } \\
\hline Control & & $2.604 \pm 0.47$ & $0.527 \pm 0.10$ & $22.79 \pm 3.72$ \\
\hline $\mathrm{CHCl}_{3}$ & & $2.063 \pm 0.38^{*}$ & $0.476 \pm 0.08$ & $17.56 \pm 1.60^{*}$ \\
\hline STZ & & $1.970 \pm 0.45^{*}$ & $0.422 \pm 0.02^{*}$ & $26.54 \pm 1.44$ \\
\hline $\mathrm{STZ}-\mathrm{CHCl}_{3}$ & & $1.748 \pm 0.20^{*}$ & $0.471 \pm 0.03$ & $21.85 \pm 3.90^{\sharp k}$ \\
\hline \multicolumn{5}{|l|}{ PB treated } \\
\hline Control & & $2.848 \pm 0.28$ & $0.746 \pm 0.16$ & $29.57 \pm 2.04$ \\
\hline $\mathrm{CHCl}_{3}$ & & $1.525 \pm 0.06^{*}$ & $0.646 \pm 0.11$ & $19.21 \pm 1.20^{*}$ \\
\hline STZ & & $2.544 \pm 0.25$ & $0.693 \pm 0.11$ & $31.46 \pm 9.57$ \\
\hline $\mathrm{STZ}+\mathrm{CHCl}_{3}$ & & $1.416 \pm 0.28^{*}$ & $0.487 \pm 0.16$ & $17.20 \pm 8.67^{*}$ \\
\hline
\end{tabular}

Values represent the mean \pm S.D. from 4 to 11 rats. Analysis of variance: ${ }^{*} \mathrm{P}<0.05$, control vs. treated: $\# \mathrm{P}<0.05, \mathrm{CHCl}_{3}$ vs. STZ $+\mathrm{CHCl}_{3}$.

Table 4. Liver cytosolic glutathione S-transferase activity in chronic diabetic rats

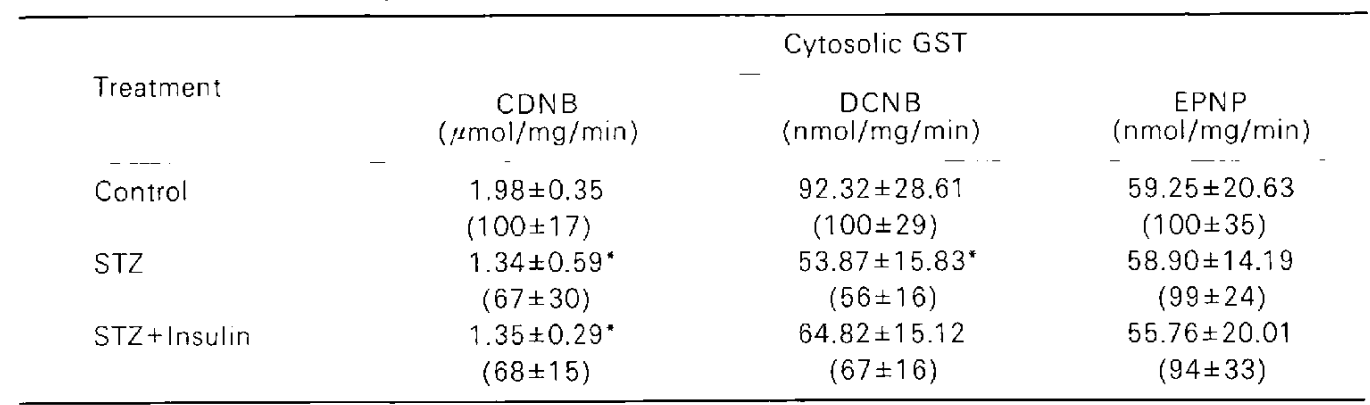

Values represent the mean \pm S.D. from 4 to 8 rats. Analysis of variance: ${ }^{*} P<0.05$ control vs. treated.

serum of diabetic rats. Serum glucose levels in the chronic diabetic and insulin-treated rats were $582.2 \pm 31.4$ and $145.5 \pm 6.3 \mathrm{mg} / \mathrm{dl}$, respectively. These results indicate that the diabetic state caused by streptozotocin was normalized by insulin treatment.

Table 4 shows liver cytosolic glutathione $S$-transferase activity in chronic diabetes. The cytosolic glutathione S-transferase activity for CDNB and for DCNB was significantly decreased to $67 \%$ and to $56 \%$ of the control, respectively, but the transferase activity for EPNP was not altered. The decrease in glutathione S-transferase activity for CDNB and DCNB was not restored by insulin treatment.

Liver microsomal glutathions S-transferase activity in chronic diabetic rats, as shown in Table 5. was significantly decreased to $75 \%$ of the control; in contrast to the cytosolic transferase, the decrease was restored to the control level by insulin treatment. The activation ability of $\mathrm{N}$-ethylmaleimide (NEM) to the microsomal glutathione S-transferase (as shown in percent of increase) was not altered in either the chronic diabetic or insulin-treated groups, and the restoration of the activity by insulin was also observed for the NEM-activated enzyme. Neither cytosolic nor microsomal glutathione 5 -transferase was altered by incubation with streptozotocin in the presence of the NADPH-generating system (Table 6).

\section{Discussion}

How a short term and long term (chronic) diabetic state in rats affects glutathions $\mathrm{S}$ transferase was investigated in combination with chloroform treatment. Hepatic glutathi- 
Table 5. Liver microsomal glutathione S-transferase activity in chronic diabetic rats

\begin{tabular}{lccc}
\hline & \multicolumn{2}{c}{ Microsomal GST for CDNB $(\mu \mathrm{mol} / \mathrm{mg} / \mathrm{min})$} \\
Treatment & unactivated & NEM-activated & $\begin{array}{c}\text { activation } \\
(\%)\end{array}$ \\
& $0.091 \pm 0.007$ & $0.680 \pm 0.072$ & $747 \pm 79$ \\
Control & $(100 \pm 8)$ & $(100 \pm 10)$ & $817 \pm 149$ \\
STZ & $0.069 \pm 0.01^{*}$ & $0.515 \pm 0.094^{*}$ & $(75 \pm 13)$ \\
STZ+Insulin & $(75 \pm 11)$ & $0.716 \pm 0.099^{\sharp}$ & $832 \pm 115$ \\
& $0.089 \pm 0.009^{*}$ & $(105 \pm 14)$ & \\
\hline
\end{tabular}

Values represent the mean \pm S.D. from 4 to 8 rats. Analysis of variance: ${ }^{*} P<0.05$. control vs. treated: $\# \mathrm{P}<0.05$, STZ vs. STZ+lnsulin.

Table 6. Effect of STZ on liver cytosolic and microsomal glutathione S-transferase activity in vitro

\begin{tabular}{|c|c|c|c|}
\hline \multirow{2}{*}{ Treatment } & \multicolumn{3}{|c|}{ GST activity for CDNB $(\mu \mathrm{mol} / \mathrm{mg} / \mathrm{min})$} \\
\hline & Cytosol & Microsomes & Cytosol+Microsomes \\
\hline Control & $1.118 \pm 0.06$ & $0.167 \pm 0.02$ & $0.137 \pm 0$ \\
\hline $\mathrm{STZ}(10 \mathrm{mM})$ & $1.141 \pm 0.04$ & $0.174 \pm 0.01$ & $0.145 \pm 0.01$ \\
\hline
\end{tabular}

Values represent the mean \pm S.D. from 3 incubations at $37^{\circ} \mathrm{C}$ for $20 \mathrm{~min}$.

one S-transferase activity was significantly decreased in the short term diabetic rats. and this decrease was additive when chloroform was administered. However, no decrease in hepatic glutathione $S$-transferase was observed in phenobarbital-treated diabetic rats (Table 3). This may be due to an induction of hepatic glutathione $S$-transferase because phenobarbital is known as a glutathione $\mathrm{S}$ transferase inducer (15). Though kidney weight increased more than liver weight, and the kidneys seemed to become hydronephrotic in short term diabetic rats, the renal cytosolic glutathione S-transferases were not altered as much as the hepatic cytosolic Stransferase. Furthermore. we observed that heart cytosolic glutathione S-transferase was not affected in streptozotocin-induced diabetic rats ( $Y$. Aniya et al., unpublished data). It is, therefore, suggested that the effect of a diabetic state on glutathione S-transferase varies according to the organ species.

Aniline hydroxylation was slightly increased in the diabetic groups and the same degree of increase in hydroxylation was reported (16). Chloroform treatment caused a significant decrease of both liver cytosolic glutathione S-transferase and microsomal aniline hydroxylase in either nontreated or phenobarbital treated rats. Since chloroform was converted to active metabolites via the cytochrome P-450 system (17), microsomal aniline hydroxylase might have been attacked suicidally by the metabolites. Potentiation of chemically-induced toxicity in the diabetic state has been previously reported $(5,7,14)$, and the potentiation was mainly attributed to an alteration of drug-metabolizing enzymes. In the present study, the potentiation of chloroform toxicity, as judged from elevated GPT and bilirubin levels in serum. was also observed in diabetic and phenobarbital treated rats. Thus, an induction of the cytochrome $P$ 450 , as shown in the small increase of aniline hydroxylase, may contribute to potentiation of chloroform toxicity in the diabetic state. In addition, the decrease of the glutathione $S$ transferase activity may play a role in potentiation of chloroform toxicity.

In order to clarify the alteration of hepatic glutathione S-transferases, we studied long term (chronic) diabetes caused by a high dose of STZ (100 mg/kg. i.p.). As judged from the alteration of blood glucose level and body 
weight, chronic diabetes is a severe diabetic condition compared to short term diabetes. Under these conditions, hepatic cytosolic glutathione S-transferase activity was decreased for CDNB and DCNB but not for EPNP. Thus, it is considered that among the several isoenzymes in the hepatic cytosol, glutathione S-transferase 3-3 or 5-5, which is known to have substrate specificity to EPNP $(1)$, is not affected by diabetes. This may mean that the diabetic state has a different effect on each isoenzyme of hepatic glutathione $\mathrm{S}$-transferase, as has been reported for cytochrome P-450 species (18-20). Furthermore, although the decrease of cytosolic glutathione S-transferase activity was not restored by insulin treatment, blood glucose level and body weight were normalized by insulin. Therefore, it is considered that hepatic cytosolic glutathione S-transferase is less sensitive to insulin than microsomal glutathione S-transferase. Concerning glutathione $\mathrm{S}$-transferase in diabetic animals, an increase in mice (21) and a decrease in rats (22) were reported. Younes et al. (22) showed that rat liver cytosolic glutathione $\mathrm{S}$-transferases in short term (4 days) diabetes were decreased and restored by insulin treatment. This difference may be, in part, due to when insulin treatment was started, because we initiated it on the third day after streptozotocin injection, but they started the treatment on the day of streptozotocin injection. A partial restoration by insulin treatment of other enzymes that had been altered in diabetic animals was reported (23).

In contrast to cytosolic glutathione Stransferase, the decreased microsomal glutathione S-transferase activity in chronic diabetes was restored by insulin treatment. This difference between cytosolic and microsomal glutathione $\mathrm{S}$-transferases in insulin treatment may reflect a difference in the regulating mechanism of both enzymes in vivo. It has been reported that insulin receptors are modified by sulfhydryl agents (24), and the hormone action may be mediated by hydrogen peroxide (25). It is well-known that hepatic microsomal glutathione S-transferase is activated by sulfhydryl agents (11). Recent data show that hydrogen peroxide increases hepatic microsomal glutathione S-transferase ac tivity (26). Thus it is assumed that the membrane-bound microsoma! glutathione $S$ transferase may be affected by insulin.

It is of interest that a decrease in hepatic glutathione S-transferase activity continues for a long time as seen in chronic diabetes. Since no release of the glutathione S-transferase into the serum was observed during diabetes, a mechamism different from chemically-induced decrease as shown in chloroform treatment may be related to the decrease of the transferase in the diabetic state. In our in vitro experiments, neither cytosolic nor microsomal glutathione S-transferase was inhibited by the addition of streptozotocin (Table 6). This means that reactive metabolites from streptozotocin formed via the cytochrome P-450 system or streptozotocin itself do not contribute to a decrease in either cytosolic or microsomal glutathione S-transferase activity. Because streptozotocin causes an impairment of DNA for insulin synthesis by free radical formation (27), the same phenomenon may occur on the gene for glutathione S-transferase. Afternatively an inhibitory regulation on glutathione $S$-transferases may be caused by metabolic changes during diabetes. Further study is needed to clarify the regulating mechanism of glutathione S-transferases in the diabetic state.

Acknowledgment: The authors thank Miss Naomi Omine for typing the manuscript.

\section{References}

1 Jakoby, W.B. and Habig, W.H.: Glutathione transferases. In Enzymatic Basis of Detoxication. Edited by Jakoby. W.B., Vol. 2, p. 63-93, Academic Press. New York (1980)

2 Habig, W.H.: Glutathione S-transferases: Versatile enzymes of detoxication. In Radioprotectors and Anticarcinogens, Edited by Nygaard. O.F. and Simic, M.G., p. 169-190. Academic Press, New York (1983)

3 Hanasono, G.K., Cote, M.G. and Plaa, G.L.: Potentiation of carbon tetrachloride-induced hepatotoxicity in alloxan- or streptozotocindiabetic rats. J. Pharmacol. Exp. Ther. 192, 592604 (1975)

4 Peng, R., Tennant, P., Lorr, N.A. and Yang, C.S.: Alterations of microsomal monooxygenase system and carcinogen metabolism by streptozotocin-induced diabetes in rats. Carcinogenesis 4. 703-708 (1983) 
5 El-Hawari, A.M. and Plaa, G.L.: Potentiation of thioacetamide-induced hepatotoxicity in alloxanand streptozotocin-diabetic rats. Toxicol. Lett. 17, 293-300 (1983)

6 Warren, B.L., Pak, R., Finlayson, M., Gontovnick, L., Sunahara, G. and Bellward, G.D.: Differential effects of diabetes on microsomal metabolism of various substrates. Comparison of streptozotocin and spontaneously diabetic Wistar rats. Biochem. Pharmacol. 32, 327-335 (1983)

7 Lorr, N.A., Miller, K.W., Chung, H.R. and Yang, C.S.: Potentiation of the hepatotoxicity of $\mathrm{N}$ nitrosodimethylamine by fasting. diabetes. acetone and isopropanol. Toxicol. Appl. Pharmacol. 73, 423-431 (1984)

8 Aniya, Y. and Anders, M.W.: Chloroform-induced alteration of glutathione S-transferase activity. Biochem. Pharmacol. 34, 249-255 (1985)

9 Aniya, Y. and Anders, M.W.: Alteration of hepatic glutathione S-transferases and release into serum after treatment with bromobenzene, carbon tetrachloride, or $\mathrm{N}$-nitrosodimethylamine. Biochem. Pharmacol. 34, 4239-4244 (1985)

10 Habig. W.H., Pabst, M.J. and Jakoby, W.B.: Glutathione S-transferase. J. Biol. Chem. 249, $7130-7139$ (1974)

11 Morgenstern, R., DePierre, J.W. and Ernster, L.: Activation of microsomal glutathione S-transferase activity by sulfhydryl reagents. Biochem. Biophys. Res. Commun. 87, 657-663 (1979)

12 Aniya, $Y$. and Matsusaki, K.: Effects of neutral salts on hepatic microsomal drug-metabolizing enzyme system in rats. Japan. J. Pharmacol. 33. 647-653 (1983)

13 Lowry, O.H., Rosebrough, N.J., Farr, A.L. and Randall, R.J.: Protein measurement with the Folin phenol reagent. J. Biol. Chem. 193, 265275 (1951)

14 Hanasono. G.K., Witschi, H. and Plaa, G.L.: Potentiation of the hepatotoxic responses to chemicals in alloxan-diabetic rats. Proc. Soc. Exp. Bial. Med. 149, 903-907 (1975)

15 Arias, I.M., Fleischner, G., Kirsch, R., Mishkim, S. and Gatmaitan, Z: On the structure, regulation. and function of ligandin. In Glutathione: Metabolism and Function. Edited by Arias. I.M. and Jakoby. W.B., p. 175-188, Raven Press. New York (1976)

16 Tanaka, E., Ishikawa, A., Misawa, S. and Kuroiwa, Y.: Sex-related differences in hepatic drug-oxidizing capacity of streptozotocininduced diabetic rats. J. Pharmacobiodyn. 11, $416-423$ (1988)
17 Pohl, L.R., Martin, J.L. and George, J.W.: Mechanism of metabolic activation of chloroform by rat liver microsomes. Biochem. Pharmacol. 29, 3271-3276 (1980)

18 Kato, R., Onoda, K. and Takanaka, A.: Species differences in drug metabolism by liver microsomes in alloxan diabetic or fasted animals. Japan. J. Pharmacol. 20, 546-553 (1970)

19 Past, M.R. and Cook, D.E.: Effect of diabetes on rat liver cytochrome P-450. Evidence for a unique diabetes-dependent rat liver cytochrome P-450. Biochem. Pharmacol. 31, 3329-3334 (1982)

20 Favreau, L.V. and Schenkman, J.B.: Decrease in the levels of a constitutive cytochrome P-450 (RLM5) in hepatic microsomes of diabetic rats. Biochem. Biophys. Res. Commun. 142, 623-630 (1987)

21 Rouer, E., Mahu, J.L., Dansette, P. and Leroux, J.P., UDP-glucuronosyltransferase, epoxide hydrolase and glutathione $S$-transferase activities in the liver of diabetic mice. Biochim. Biophys. Acta 676, 274-277 (1981)

22 Younes, M., Schlichting, R. and Siegers, C.-P.: Glutathione $\mathbf{S}$-transferase activities in rat liver: Effect of some factors influencing the metabolism of xenobiotics. Pharmacol. Res. Commun. 12, 115-129(1980)

23 Rouer, E. and Leroux, J.P.: Liver microsomal cytochrome P-450 and related monooxygenase activities in geretically hyperglycemic (ob/ob and $\mathrm{db} / \mathrm{db}$ ) and lean streptozotocin-treated mice. Biochem. Pharmacol. 29, 1959-1962 (1980)

24 Czech, M.P., Lawrence, J.C., Jr. and Lynn, W.S.: Evidence for the involvement of sulfhydryl oxidation in the regulation of fat cell hexose transport by insulin. Proc. Natl. Acad. Sci. U.S.A. 71, 4173-4177 (1974)

25 May, J.M. and Haen, C.: Insulin-stimulated intracelluar hydrogen peroxide production in rat epididymal fat cells. J. Biol. Chem. 254, 2214 2220 (1979)

26 Aniya, Y. and Anders, M.W.: Activation of rat liver microsomal glutathione S-transferase by reduced oxygen species. J. Biol. Chem. 264, 1998-2002 (1989)

27 Uchigata, Y., Yamamoto, H., Kawamura, A. and Okamoto, H.: Protection by superoxide dismutase, catalase. and poly (ADP-ribose) synthetase inhibitors against a!loxan- and streptozotocininduced islet DNA strand breaks and against the inhibition of proinsulin synthesis. J. Biol. Chem. $257,6084-6088(1982)$ 